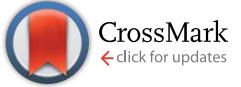

Cite this: RSC Adv., 2017, 7, 3838
Received 26th October 2016 Accepted 6th December 2016

DOI: $10.1039 / c 6 r a 25859 j$

www.rsc.org/advances

\section{Beauveria bassiana (Clavicipitaceae): a potent fungal agent for controlling mosquito vectors of Anopheles stephensi, Culex quinquefasciatus and Aedes aegypti (Diptera: Culicidae)}

\begin{abstract}
Chinnasamy Ragavendran, ${ }^{a}$ Nawal Kishore Dubey ${ }^{b}$ and Devarajan Natarajan*a
Mosquitoes are the carriers of severe and well-known illnesses such as malaria, arboviral encephalitis, dengue, chikungunya and yellow fever, which cause significant morbidity and mortality in humans and domestic animals around the world. Entomopathogenic fungal metabolites act as a mosquito control agent and are potential alternatives to chemical control because they can be innovative and more selective than chemical insecticides. The main aim of the present study was to perform experiments on the larvicidal and pupicidal effects of the entomopathogenic fungus Beauveria bassiana (isolated from infected grasshopper) against the first to fourth instar larvae of Anopheles stephensi, Culex quinquefasciatus and Aedes aegypti. The larval and pupal mortality were observed after $24 \mathrm{~h}$ of exposure. The efficacy of an ethyl acetate mycelium extract at all the tested concentrations (50, 100, 150, 200, 250 and $300 \mu \mathrm{g} \mathrm{mL}^{-1}$ ) exhibited better activity against the $1^{\text {st }}$ to $4^{\text {th }}$ instar larvae of $A n$. stephensi $\left(\mathrm{LC}_{50}=42.82,39.45,25.72\right.$, and 32.66; $\mathrm{LC}_{90}=254.67,367.11,182.27$, and $199.20 \mu \mathrm{g} \mathrm{mL}^{-1}$ ), Cx. quinquefasciatus $\left(\mathrm{LC}_{50}=72.38,68.11,27.06\right.$, and 35.495; $\mathrm{LC}_{90}=481.68,254.69,129.83$, and 146.24 $\left.\mu \mathrm{g} \mathrm{mL}^{-1}\right)$ and Ae. aegypti $\left(\mathrm{LC}_{50}=62.50,52.89,58.60\right.$, and 47.12; $\mathrm{LC}_{90}=314.82,236.18,247.53$, and $278.52 \mu \mathrm{g} \mathrm{mL}^{-1}$ ), respectively. The pupicidal activity of the fungal mycelium extracts was tested against An. stephensi, Cx. quinquefasciatus and Ae. Aegypti, where the ethyl acetate extracts had different $L_{50}$ values $\left(\mathrm{LC}_{50}=40.66,54.06,44.26\right.$, and $\mathrm{LC}_{90}=184.02,225.61$, and $\left.263.02 \mu \mathrm{g} \mathrm{mL}{ }^{-1}\right)$. Based on Fourier transform infrared spectroscopy (FTIR) analysis and gas chromatography-mass spectrometry (GC-MS) analyses, the ethyl acetate mycelium extract contained six major chemical compounds identified as 9,12-octadecadienoic acid (ZZ)- (63.16\%), n-hexadecanoic acid (21.28\%), octadecanoic acid, phenyl methyl ester (10.45\%), dehydroegosterol 3,5-dinitrobenzoate (1.86\%), squalene (1.66\%) and bis[3-(3,5-ditert-butyl-4-hydroxyphenyl)prophyl]maleate (1.56\%). The $n$-hexadecanoic acid standard was found to be better larvicidal against An. stephensi, Cx. quinquefasciatus, followed by Ae. aegypti. The HPLC analysis of the ethyl acetate mycelium extract was compared with that of the $n$-hexadecanoic acid standard and it was found to show a similar chromatographic peak (at a retention time of 3.383 and $3.378 \mathrm{~min}$ ). The outcome of the present study identifies the bioactive compounds obtained from $B$. bassiana that can be used as effective and alternate larvicidal and pupicidal agents against the An. stephensi Cx. quinquefasciatus and Ae. aegypti mosquito vectors.
\end{abstract}

\section{Introduction}

Vector-borne diseases are illnesses caused by pathogens and parasites in human populations. Globally, every year there are about more than 1 billion cases and over 1 million deaths due to vector-borne diseases, such as malaria, dengue, schistosomiasis, human African trypanosomiasis, leishmaniasis, chagas disease,

${ }^{a}$ Natural Drug Research Laboratory, Department of Biotechnology, School of Biosciences, Periyar University, Salem - 636 011, Tamil Nadu, India. E-mail: mdnataraj@rediffmail.com; natarajpu@gmail.com

${ }^{b}$ Centre of Advanced Study in Botany, Banaras Hindu University, Varanasi-221005, India yellow fever, Japanese encephalitis and onchocerciasis. Vectorborne diseases account for over $17 \%$ of all infectious diseases. Malaria is a parasitic disease spread by infected Anopheles mosquitoes, which is caused by parasite species namely Plasmodium falciparum, $P$. vivax, $P$. malariae and $P$. ovale. ${ }^{1}$ Malaria causes symptoms that typically include fever and headache, which in severe cases can lead to coma or death. A recent survey released in December 2014 reported about 198 million cases of malaria in 2013 with an uncertainty range from 124 million to 283 million and an estimated 584000 deaths (with an uncertainty range of 367000 to 755000 ). Malarial mortality rates have fallen globally by $47 \%$ since 2000 and $54 \%$ reported in the African regions. ${ }^{2}$ 
Culex mosquitoes are painful and persistent biters and are responsible for filariasis. Lymphatic filariasis is a neglected tropical disease. Lymphatic filariasis is commonly known as elephantiasis and infection occurs when filarial parasites are transmitted to humans through mosquitoes. ${ }^{3}$ When a mosquito with infective stage larvae bites a person, the parasites are deposited on the person's skin from where they enter into the body. The larvae then migrate to the lymphatic vessels where they develop into adult worms in the lymphatic system. Worldwide, more than 1.3 billion people from 72 countries are threatened by lymphatic filariasis, commonly known as elephantiasis. ${ }^{4}$ Chikungunya is a viral tropical disease transmitted by Aedes mosquitoes. The disease is prevalent in Africa, Asia, the islands in the Caribbean, India and Pacific oceans. Typical symptoms are an acute illness with fever, skin rash and incapacitating joint pain that can last for weeks. ${ }^{5}$ The latter distinguishes chikungunya virus from dengue, which otherwise shares the same vectors, symptoms and geographical distribution. There is no cure or commercial vaccine for the disease. Most patients recover fully; however, in some cases, joint pain may persist for several months or even years. As with dengue, the only method to reduce the transmission of the chikungunya virus is to control vector mosquitoes and protect against mosquito bites. Yellow fever is an acute viral hemorrhagic disease transmitted by Aedes mosquitoes. The "yellow" in the name refers to the jaundice that affects some patients. There are an estimated 200000 cases of yellow fever, which cause 30000 deaths worldwide per year. The virus that causes yellow fever is endemic in densely populated countries, viz., Tropical Africa and Latin America. Small numbers of imported cases occur in countries free of yellow fever. ${ }^{6}$

The common control agents for mosquito larvicides are mainly dependent on chemical methods using synthetic insecticides that are likely to include, organophosphates such as temephos, fenthion, phytochemicals and insect growth regulators such as diflubenzuron, and methoprene. ${ }^{7}$ However, most of these synthetics have adverse effects on the environment. Due to their residual nature there are reports on the development of pesticide resistance in mosquitoes ${ }^{8}$ rendering them ineffective for further applications. These problems encourage the search for safer and better alternative bioactive larvicidal agents. Although various biocontrol measures are in vogue, to date, their effective control of larval mosquitoes has not been practically highlighted. Microbial control is recommended as an alternative way, and microbial based larvicides are employed for minimizing the mosquito population, which provides an effective, environmentally friendly and sociable approach to bring the mosquito population to the lowest level. ${ }^{\mathbf{9}, 10}$

Beauveria bassiana (Clavicipitaceae) is a soil borne fungus that feeds on insects and can be used effectively to control thrips, aphids, whitefly, caterpillars, beetles, and subterranean insects like ants and termites. B. bassiana is non-toxic to mammals, birds and plants, and its use is not expected to have any deleterious effects on human health or the environment. ${ }^{11}$ Conidia of $B$. bassiana has been reported to be effective in killing mosquito larvae when applied as conidia dust in the breeding sites. Besides infecting larvae, the fungus has also proven to be virulent to adult mosquitoes. ${ }^{12} \mathrm{~B}$. bassiana is applied to the target pest as a spore, which is the reproductive and dispersal structure of the fungus. Once the spores have made contact with the insect exoskeleton, they grow hyphae (long, branching vegetative appendages) that secrete enzymes, which in turn dissolve the cuticle (outermost layer of the skeleton). These fungal hyphae grow into the insect, feed on its body tissue, produce toxins, and reproduce. It takes up to seven days for the insect to die. During favorable (moist) conditions (92\% humidity or greater), B. bassiana will "bloom" and release more spores into the environment to repeat the cycle on other pest insects. ${ }^{13}$ The species of Beauveria has been reported to produce secondary metabolites, including bassianin, bassiacridin, beauvericin, bassianolide, beauverolides, tenellin and oosporein. ${ }^{14-16}$ It also produces proteases, chitinases and lipases, which can degrade the insect cuticle. ${ }^{17}$ In this regard, the entomopathogenic fungi, viz., Aspergillus flavus, A. parasiticus, Penicillium falicum, Fusarium vasinfectum and Trichoderma viride and soil bacteria, Bacillus thuringiensis and B. sphaericus have

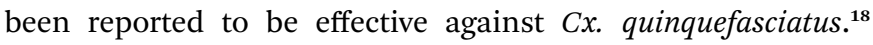
Hence, the present study was focused on the insecticidal potential of Beauveria bassiana mycelial extracts against target mosquitoes.

\section{Materials and methods}

\section{Isolation and identification of entomopathogenic fungus}

The entomopathogenic fungus $B$. bassiana was isolated from an infected grasshopper (Melanoplus sanguinipes) collected from an agricultural field (latitude $11.6500^{\circ} \mathrm{N}$, longitude $78.1600^{\circ} \mathrm{E}$ ) in the Salem District, Tamilnadu, India. The cadaver was placed on potato dextrose agar (PDA (Hi-Media)) supplemented with streptomycin $(1 \mathrm{mg} / 100 \mathrm{~mL})$ and incubated for 7 days at $27^{\circ} \mathrm{C} \pm$ $2{ }^{\circ} \mathrm{C} .{ }^{19}$ After 7 days of incubation, the pure culture of $B$. bassiana was subcultured into PDA using the streak plate method. The isolated culture was identified using the slide culture method subjected to lactophenol cotton blue staining and observed under a light microscope (Labomed). Mycotaxonomic keys followed by Samson ${ }^{20}$ and Samson et al. ${ }^{21}$ were used to identify the fungus.

\section{Morphological identification of B. bassiana}

The fungus was primarily identified based on its morphological features, descriptions of species, keys to taxa and additional information from "Studies in Mycology". ${ }^{22}$ Colonies of $B$. bassiana fungus were cultivated on Sabouraud's dextrose agar at $25{ }^{\circ} \mathrm{C}$ for 7 days. The following morphological characteristics were assessed: colony growth (length and width), the presence or absence of aerial mycelium, colony color, presence of wrinkles, furrows and pigment production. ${ }^{21}$

\section{Preparation of Sabouraud's dextrose broth and mass culture of $B$. bassiana}

The broths were prepared for the culture of fungus as per the modified method of Gardner and Pillai. ${ }^{23}$ B. bassiana was grown 
in Sabouraud's Dextrose Broth (SDB). Ten $250 \mathrm{~mL}$ conical flasks, each containing $100 \mathrm{~mL}$ of SDB (dextrose $40 \mathrm{~g}$, peptone $10 \mathrm{~g}$, deionized water $1000 \mathrm{~mL}$ ), autoclaved at $20 \mathrm{psi}$ for $20 \mathrm{~min}$. The broths were supplemented with $50 \mu \mathrm{g} \mathrm{mL}{ }^{-1}$ chloramphenicol, which acted as a bacteriostatic agent. The $B$. bassiana colonies grown on the Sabouraud's dextrose agar plates were transferred to each flask (using an inoculation needle). The conical flasks inoculated with $B$. bassiana were incubated at $25{ }^{\circ} \mathrm{C}$ for 25 days.

\section{Secondary metabolite extraction from $B$. bassiana}

Mass cultivation of the fungus was carried out in a $250 \mathrm{~mL}$ Erlenmeyer flask containing $100 \mathrm{~mL}$ of Sabouraud's dextrose broth medium. The culture flasks were incubated under the optimized culture conditions ( $\mathrm{pH} 7.0$, temperature $27^{\circ} \mathrm{C}$ ) for 25 days. For the liquid culture, the fungal mycelium mat was washed three times with sterile distilled water to remove adherent filtrate and subjected to an extraction of biologically active components using ethyl acetate and methanol solvents. The solvents were mixed to the mycelia mat for cold extraction for 7 days at room temperature. After thorough mixing, the immiscible portion of ethyl acetate (pale yellow colored) was separated from the mycelium. The mycelium was filtered through Whatmann no. 1 filter paper. The separated portions of ethyl acetate and methanol extracts were finally dried using a rotary vacuum evaporator at $45^{\circ} \mathrm{C}$ as per the modified method of Belofsky et al. (2000). ${ }^{24}$

\section{Larvae collection and rearing}

For the laboratory trial, the different $\left(1^{\text {st }}\right.$ to $\left.4^{\text {th }}\right)$ instar larvae stages of An. stephensi, Cx. quinquefasciatus and Ae. aegypti were obtained from the Institute of Vector Control and Zoonoses, (IVCZ), (latitude $12.7200^{\circ} \mathrm{N}$, longitude $77.8200^{\circ} \mathrm{E}$ ), Hosur, Tamilnadu, India. The larvae were kept in plastic enamel trays containing dechlorinated tap water. They were maintained as per the previous report of Patil et al. ${ }^{25}$ The larvae were fed on dog biscuits and yeast powder in 3:1 ratio. Adults were fed with blood through a paraffin membrane and provided with $10 \%$ sucrose solution. Mosquitoes were kept at $28{ }^{\circ} \mathrm{C} \pm 2{ }^{\circ} \mathrm{C}$ and $70-$ $85 \%$ relative humidity with a photoperiod of $12 \mathrm{~h}$ light/12 h dark.

\section{Larvicidal bioassay}

The larval mortality bioassays were carried out according to the method suggested by the World Health Organization ${ }^{\mathbf{2 6}}$ with slight modifications. ${ }^{27}$ Sufficient amounts of ethyl acetate and methanol extracts were transferred to a vial, and the residual solvent was removed under high vacuum. Stock solutions of each test mycelium extract in dimethyl sulfoxide (DMSO) were prepared with a concentration of $10 \% \mathrm{w} / \mathrm{v}(1 \mathrm{mg}$ of extracts in $1000 \mu \mathrm{L}$ of DMSO) prepared into five different concentrations viz. 50, 100, 150, 250 and $300 \mu \mathrm{g} \mathrm{mL}{ }^{-1}$ with distilled water at $\mathrm{pH}$ 7.0. Twenty numbers of late first to early fourth-instar mosquito larvae were placed in a $2 \% \mathrm{v} / \mathrm{v}$ aqueous solution of DMSO (99 $\mathrm{mL}$ of distilled water plus $1 \mathrm{~mL}$ of DMSO), followed by the addition of the test solutions. Five replicates per dose were maintained, and a treatment with $99 \mathrm{~mL}$ of tap water and $1 \mathrm{~mL}$ of DMSO was added to each bioassay as the control at $\mathrm{pH}$ 7.0. During this experiment, no food was provided to the larvae. The larval mortality was calculated after $24 \mathrm{~h}$ of exposure.

$$
\text { Corrected mortality }=
$$

$\frac{\text { observed mortality in treatment - observed mortality in control }}{100-\text { control mortality }}$ 100 - control mortality

$\times 100$

\section{Pupal toxicity tests}

The laboratory colony of mosquito pupae was used to test the pupicidal activity of the B. bassiana extracts. Twenty freshly emerged pupae were kept in a $100 \mathrm{~mL}$ glass beaker containing $99 \mathrm{~mL}$ of dechlorinated water and a different concentrations of mycelium extracts $\left(50,100,150,200,250\right.$ and $\left.300 \mu \mathrm{g} \mathrm{mL}^{-1}\right)$. The experiment consists of five replicates; the control containing 1 $\mathrm{mL}$ of DMSO in $99 \mathrm{~mL}$ of dechlorinated water at $\mathrm{pH}$ 7.0. The mortality in the treatments and control was corrected using Abbott's formula. ${ }^{28}$ The $\mathrm{LC}_{50}$ and $\mathrm{LC}_{90}$ were calculated from toxicity data using probit analysis. ${ }^{29}$

$$
\begin{aligned}
\text { Percentage of mortality }= & \frac{\text { number of dead larvae/pupae }}{\text { number of larvae/pupae introduced }} \\
& \times 100
\end{aligned}
$$

\section{Dose response bioassay}

The stock solutions obtained from the mycelia extract at different concentrations (ranging from 50 to $300 \mu \mathrm{g} \mathrm{mL}{ }^{-1}$ ) were prepared as per the method of Rahuman et al. ${ }^{30}$ Based on the preliminary screening results, the mycelium extracts of $B$. bassiana were subjected to a dose-response bioassay for larvicidal and pupicidal activity against first to fourth instar larvae and pupae of An. stephensi, Cx. quinquefasciatus and Ae. aegypti. The number of dead larvae were counted after $24 \mathrm{~h}$ of exposure, and the percentage mortality was reported from the average of five replicates.

\section{Preparation of the standard}

$n$-Hexadecanoic acid was procured from Sigma, USA and DMSO was used as the solvent to prepare the stock solution. The stock solution was diluted further to produce the required concentrations to perform the bioassay tests. ${ }^{31}$

\section{Control experiment (Acremonium sp. non-pathogenic fungi)}

The larval and pupal mortality bioassays of Acremonium sp. were carried out according to the method suggested by the World Health Organization with slight modifications. ${ }^{26,27}$ A sufficient amount of the Acremonium sp. ethyl acetate extracts was transferred to a vial, and the residual solvent was removed under high vacuum. The stock solution of Acremonium mycelial ethyl acetate extract was prepared using dimethyl sulfoxide (DMSO) with a concentration of $10 \% \mathrm{w} / \mathrm{v}(1 \mathrm{mg}$ of extracts in $1000 \mu \mathrm{L}$ of DMSO). Then, it was diluted into five different concentrations, viz., 50, 100, 150, 250 and $300 \mu \mathrm{g} \mathrm{mL}{ }^{-1}$, and used for bioassay. 


\section{Fourier transformed infrared spectroscopy (FTIR)}

$1.0 \mathrm{mg}$ of sample was mixed with $100 \mathrm{mg}$ of $\mathrm{KBr}$ (binding agent) using a clean mortar and a pestle to produce a powder. The powder was made into pellets using a hydraulic press. The pellets were then subjected to FTIR analysis on a BRUKER $\alpha$-T FTIR spectrometer. The precision of the FTIR spectra was better than $0.09 \mathrm{~cm}^{-1}$ and the scanning range was from 4000 to 500 $\mathrm{cm}^{-1} .^{32}$ FTIR analysis was carried out in the Department of Physics, Periyar University, Salem, Tamilnadu, India.

\section{Gas chromatography-mass spectrophotometry (GC-MS) analysis}

GC-MS analysis of the samples was carried out on a Perkin Elmer (clarus 680) series GC-MS (Marathon, USA) system equipped with clarus 600 (EI) auto-sampler coupled with an Elite-5 MS capillary column $(30 \mathrm{~m} \times 0.25 \mathrm{~mm}$ i.d., and 0.250 $\mu \mathrm{m})$ (PerkinElmer, Inc, made in USA). Helium was used as the carrier gas at a flow rate of $1 \mathrm{~mL} \mathrm{~min}^{-1}$; split ratio of $10: 1$; mass scan 50-600 Da; ionization energy, $70 \mathrm{eV}$; ion source temperature, $240{ }^{\circ} \mathrm{C}$; injector temperature, $250{ }^{\circ} \mathrm{C}$. The oven temperature was programmed as follows: initially at $60{ }^{\circ} \mathrm{C}$ for $2 \mathrm{~min}$, rising at $10{ }^{\circ} \mathrm{C} \min ^{-1}$ to $300{ }^{\circ} \mathrm{C}$ and then held isothermally (6 min) at $300{ }^{\circ} \mathrm{C}$ with a total run time of $32 \mathrm{~min}$. The percentage composition of the crude extract constituents was expressed as a percentage of the peak area. The chemical compounds were identified and characterized based on their retention time (RT). The obtained mass spectral data (GC-MS) was matched with those of standards available in the existing computer library (NIST) data base. ${ }^{33}$ The GC-MS analysis was carried out in the Sophisticated Instrument Facility, (SAIF). Vellore Institute of Technology (VIT), Vellore, Tamilnadu, India.

\section{High performance liquid chromatography (HPLC) analysis}

The $B$. bassiana mycelium ethyl acetate extract and pure $n$-hexadecanoic acid were diluted and subjected to high performance liquid chromatography (HPLC) analysis. For the chromatographic analysis of ethyl acetate extract and pure $n$-hexadecanoic acid, the samples were detected using an LC-20AD HPLC system (Shimadzu Chromatographic Instruments, Japan) equipped with a C18 reverse phase column (particle size: $5 \mu \mathrm{m}$; length: $4.6 \times 250 \mathrm{~mm}$ ) and a SPD-20A UV/Vis detector at $242 \mathrm{~nm}$ absorbance with methanol : water $(50: 50)$ at a flow rate of $1 \mathrm{~mL}$ $\mathrm{min}^{-1}$ and head pressure of $300 \mathrm{kgf} \mathrm{cm}^{-2}$. The entire instrument room setup was maintained at room temperature $\left(23^{\circ} \mathrm{C}\right)$ following the method of Junaid Khan et al. ${ }^{34} n$-Hexadecanoic acid was used as the standard. The amount of specific compounds that resembles the standard was expressed as micrograms per gram.

\section{Statistical analysis}

The percentage of larval mortality was calculated using the Abbott formula. ${ }^{28}$ The dose-response data were subjected to probit regression analysis ${ }^{29}$ for calculating the $\mathrm{LC}_{50}, \mathrm{LC}_{90}, 95 \%$ fiducial limits of upper confidence limit and lower confidence limit, and the chi-square values were calculated using the IBM
SPSS (Statistical Package of Social Sciences) software version 20.0 developed by Reddy et al. ${ }^{35}$ Results with $P<0.05$ were considered to be statistically significant.

\section{Results}

The fungal strain was isolated from an infected grasshopper, Melanoplus sanguinipes. The SDA plates showed (after incubation) a fungus with white fluffy cottony growth with pale yellow edges. The piece of mycelium was stained with lactophenol cotton blue and observed under a microscope (Lobomed, 40×) showing abundant conidiospores arising from the vegetative hyphae, bearing groups of clustered conidiogenous cells with the apical zig-zag appearance, branched to give rise to further conidiogenous cells; globose to flask-shaped, one-celled spherical conidia were recorded. Previously Hermanides ${ }^{36}$ and Seyed Ali Safari ${ }^{37}$ identified B. bassiana using fungal key manual 'Studies in Mycology'.

The larvicidal activity of mycelium ethyl acetate and methanol extracts obtained from $B$. bassiana was investigated. The ethyl acetate mycelium extract had a promising larvicidal activity (Table 1 ) against the $1^{\text {st }}$ to $4^{\text {th }}$ instar larvae (after $24 \mathrm{~h}$ of exposure period) on An. stephensi $\left(\mathrm{LC}_{50}=42.82,39.45,25.72\right.$, and 32.66; $\mathrm{LC}_{90}=254.67,367.11,182.27$ and $199.20 \mu \mathrm{g} \mathrm{mL}^{-1}$ ) Cx. quinquefasciatus $\left(\mathrm{LC}_{50}=72.38,68.11,27.06\right.$, and 35.495; $\mathrm{LC}_{90}=481.68,254.69,129.83$, and $\left.146.24 \mu \mathrm{g} \mathrm{mL}^{-1}\right)$ and $A e$. aegypti $\left(\mathrm{LC}_{50}=62.50,52.89,58.60\right.$, and 47.12; $\mathrm{LC}_{90}=314.82$,

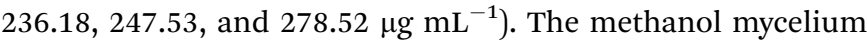
extract (Table 2) showed considerable mortality against the vector mosquitoes i.e. An. stephensi, which had the better $\mathrm{LC}_{50}$ and $\mathrm{LC}_{90}$ values $\left(\mathrm{LC}_{50}=65.22,68.96,67.64\right.$ and 52.95; $\mathrm{LC}_{90}=$ 317.77, 431.59, 345.35 and $687.70 \mu \mathrm{g} \mathrm{mL}^{-1}$ ) followed by $C x$. quinquefasciatus $\left(\mathrm{LC}_{50}=98.56,80.85,61.72\right.$ and $41.16 ; \mathrm{LC}_{90}=$ $678.66,399.97,336.85$ and $\left.470.47 \mu \mathrm{g} \mathrm{mL}{ }^{-1}\right)$ and $A e$ aegypti $\left(\mathrm{LC}_{50}\right.$ $=64.94,72.61,61.90$ and 57.65 $; \mathrm{LC}_{90}=961.97,901.21,439.32$ and $916.04 \mu \mathrm{g} \mathrm{mL}{ }^{-1}$ ). At a concentration of less than $50 \mu \mathrm{g} \mathrm{mL}^{-1}$ from $B$. bassiana, the mortality rates were slower, but the larvae became very slow-moving when compared with the control. The sub-lethal effects on the first and second larval instars were correlated with the minimum survival of the third and fourth instar larvae. The third and fourth instars larvae were also susceptible in the bioassay at the lowest lethal concentration. The dose dependent assay results showed that maximum $(100 \%)$ mortality was obtained at a higher concentration $(300 \mu \mathrm{g}$ $\mathrm{mL}^{-1}$ ) against the different stages of instar larvae of the $A n$. stephensi, Cx. quinquefasciatus and Ae. aegypti mosquitoes. At a higher concentration of extracts, the mortality rate was exhibited within $5 \mathrm{~h}$ of exposure. More than $50 \%$ mortality was observed within the first $10 \mathrm{~h}$. The control showed a nil mortality in the concurrent assay. The $\chi^{2}$ value was significant at the $P<0.05$ level.

The results of the pupal mortality of mosquitoes (Table 3) were tested with six different concentrations $\left(50\right.$ to $300 \mu \mathrm{g} \mathrm{mL} \mathrm{m}^{-1}$ ) of the fungus extracts. The fungal ethyl acetate mycelium extracts show better results against An. stephensi $\left(\mathrm{LC}_{50}=40.66\right.$; $\left.\mathrm{LC}_{90}=184.02 \mu \mathrm{g} \mathrm{mL}^{-1}\right)$ followed by $C x$. quinquefasciatus $\left(\mathrm{LC}_{50}=\right.$ 54.06; $\left.\mathrm{LC}_{90}=225.61 \mu \mathrm{g} \mathrm{mL} \mathrm{mL}^{-1}\right)$ and Ae. aegypti $\left(\mathrm{LC}_{50}=44.26\right.$; 
Table 1 The larvicidal activity of $B$. bassiana fungal mycelium extract (ethyl acetate) against the larvae of An. stephensi, Cx. quinquefasciatus and Ae. aegypti (after $24 \mathrm{~h}$ of exposure) ${ }^{a}$

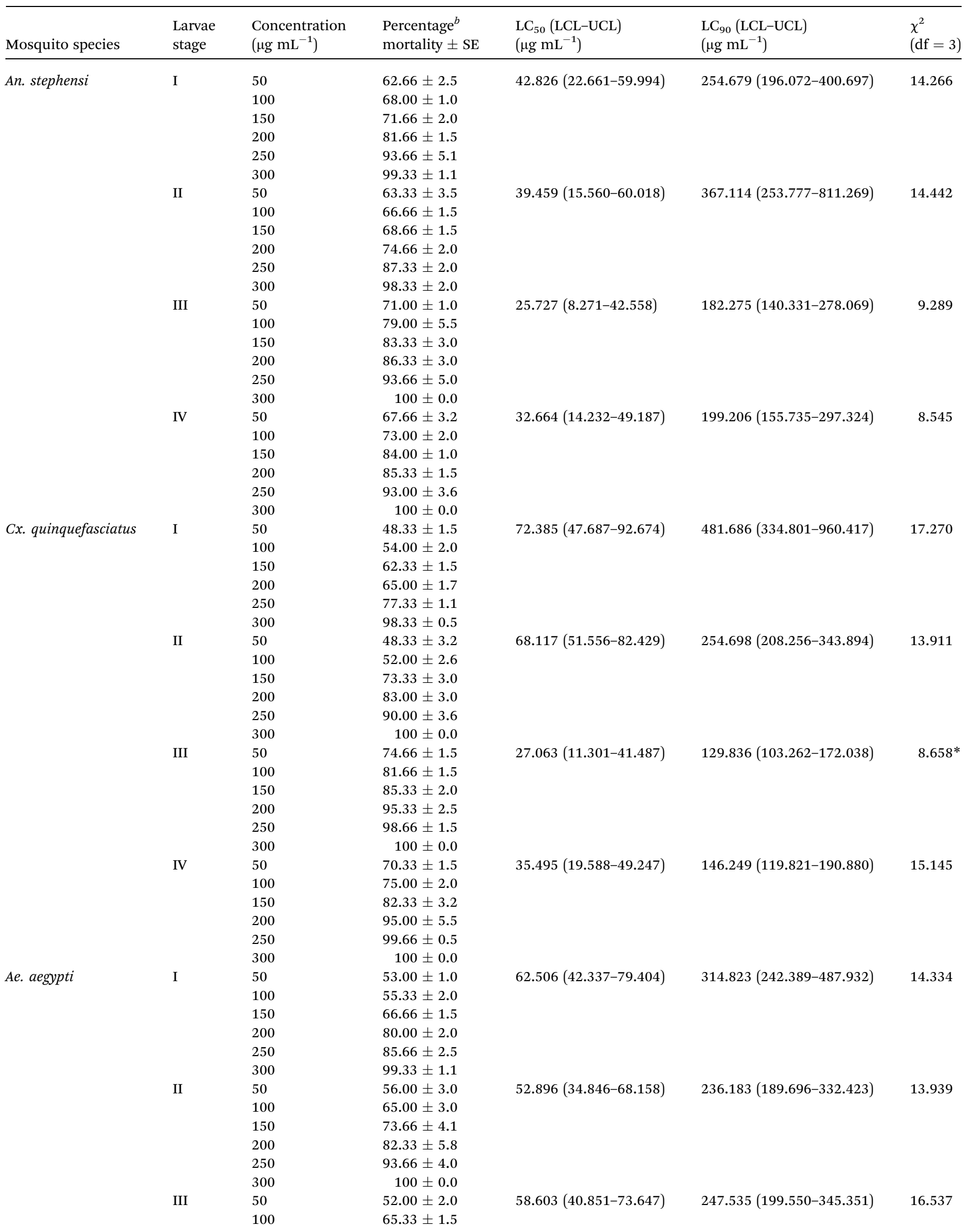


Table 1 (Contd.)

\begin{tabular}{|c|c|c|c|c|c|c|}
\hline Mosquito species & $\begin{array}{l}\text { Larvae } \\
\text { stage }\end{array}$ & $\begin{array}{l}\text { Concentration } \\
\left(\mu \mathrm{g} \mathrm{mL}^{-1}\right)\end{array}$ & $\begin{array}{l}\text { Percentage }^{b} \\
\text { mortality } \pm \text { SE }\end{array}$ & $\begin{array}{l}\mathrm{LC}_{50}(\mathrm{LCL}-\mathrm{UCL}) \\
\left(\mu \mathrm{g} \mathrm{mL}^{-1}\right)\end{array}$ & $\begin{array}{l}\mathrm{LC}_{90}(\mathrm{LCL}-\mathrm{UCL}) \\
\left(\mu \mathrm{g} \mathrm{mL}^{-1}\right)\end{array}$ & $\begin{array}{l}\chi^{2} \\
(\mathrm{df}=3)\end{array}$ \\
\hline & \multirow{7}{*}{ IV } & 150 & $68.33 \pm 2.0$ & \multirow{7}{*}{$47.125(26.419-64.574)$} & \multirow{7}{*}{$278.528(212.833-445.541)$} & \multirow{7}{*}{15.999} \\
\hline & & 250 & $94.00 \pm 4.5$ & & & \\
\hline & & 300 & $100 \pm 0.0$ & & & \\
\hline & & 50 & $57.00 \pm 1.0$ & & & \\
\hline & & 200 & $78.66 \pm 0.5$ & & & \\
\hline & & 250 & $87.66 \pm 1.5$ & & & \\
\hline & & 300 & $100 \pm 0.0$ & & & \\
\hline
\end{tabular}

${ }^{a}$ Control (deionized water) - nil mortality. $\mathrm{LC}_{50}$ - lethal concentration that kills $50 \%$ of the exposed larvae, $\mathrm{LC}_{90}-$ lethal concentration that kills $90 \%$ of the exposed larvae, $\mathrm{LCL}=$ lower confidence limit, $\mathrm{UCL}=$ upper confidence limit, df degree of freedom, ${ }^{*} \chi^{2}$ - chi-square values are significant at $P$ $<0.05$ levels. ${ }^{b}$ The mean value of five replicates $( \pm \mathrm{SE})$.

$\mathrm{LC}_{90}=263.02 \mu \mathrm{g} \mathrm{mL} \mathrm{m}^{-1}$ ) (Fig. 1), whereas the methanol extract revealed moderate pupicidal effects against An. stephensi $\left(\mathrm{LC}_{50}\right.$ $\left.=51.92 ; \mathrm{LC}_{90}=1196 \mu \mathrm{g} \mathrm{mL} \mathrm{m}^{-1}\right), C x$. quinquefasciatus $\left(\mathrm{LC}_{50}=\right.$ 69.29; $\left.\mathrm{LC}_{90}=862.25 \mu \mathrm{g} \mathrm{mL}{ }^{-1}\right)$ and Ae. aegypti $\left(\mathrm{LC}_{50}=76.34\right.$; $1178.15 \mu \mathrm{g} \mathrm{mL}{ }^{-1}$ ), (Table 4). At the concentrations of $300 \mu \mathrm{g}$ $\mathrm{mL}^{-1}$ for the B. bassiana ethyl acetate constituents, about $90 \%$ of the mortality was observed within $18 \mathrm{~h}$ for An. stephensi and $C x$. quinquefasciatus, followed by Ae. Aegypti, and a $100 \%$ pupal mortality was observed at the higher concentration of the extracts. The pupal toxicity revealed a dose-dependent mortality in the treatment against the An. stephensi, Cx. quinquefasciatus and Ae. aegypti. Based on the results, the ethyl acetate extract obtained from the fungal species was found to be an excellent pupicidal agent against the targeted mosquitoes An. stephensi, Cx. quinquefasciatus and Ae. aegypti.

In addition, the toxicity of the $n$-hexadecanoic acid standard was tested against An. stephensi, Cx. quinquefasciatus and Ae. aegypti. The $\mathrm{LC}_{50}$ values of $n$-hexadecanoic acid against the first, second, third and fourth instar larvae of An. stephensi $\left(\mathrm{LC}_{50}=\right.$ 50.22, 58.72, 2.27 and 38.61; $\mathrm{LC}_{90}=105.09,148.19,15.910$ and 81.98 ) and $C x$. quinquefasciatus $\left(\mathrm{LC}_{50}=10.64,23.23,12.75\right.$ and $0.72 ; 39.82,55.53,38.47$ and 5.18) followed by Ae. aegypti $\left(\mathrm{LC}_{50}\right.$ $=5.53,12.46,8.13$ and $9.41 ; 21.25,33.75,30.57$ and $27.36 \mu \mathrm{g}$ $\mathrm{mL}^{-1}$ ) were recorded from present investigation. Similar observations were made for the pupicidal activity against $A n$. stephensi, Cx. quinquefasciatus and Ae. aegypti; the $\mathrm{LC}_{50}$ and $\mathrm{LC}_{90}$ values were represented as follows: $8.66,0.69,3.05 ; 28.86,4.38$ and $11.43 \mu \mathrm{g} \mathrm{mL}^{-1}$, respectively. $n$-Hexadecanoic acid was found to show effective insecticidal activity against $A n$. stephensi and $C x$. quinquefasciatus, followed by Ae. aegypti.

Simultaneously, the Acremonium mycelium ethyl acetate extract showed larvicidal effects after $24 \mathrm{~h}$ of exposure. Considerable mortality was evident after the treatment of Acremonium for $1-4^{\text {th }}$ instar larvae of three important mosquitoes. The $\mathrm{LC}_{50}$ and $\mathrm{LC}_{90}$ values of the first, second, third and fourth instars of An. stephensi $\left(\mathrm{LC}_{50}=11.38,8.18,8.56\right.$ and 5.30; $\mathrm{LC}_{90}=22.42,17.19,17.23$ and $\left.11.84 \mu \mathrm{g} \mathrm{mL}{ }^{-1}\right) ; C x$. quinquefasciatus $\left(\mathrm{LC}_{50}=10.11,13.35,4.01\right.$ and 8.06; $\mathrm{LC}_{90}=20.23$, 25.13, 9.83 and $\left.17.83 \mu \mathrm{g} \mathrm{mL} \mathrm{mL}^{-1}\right)$ and Ae. aegypti $\left(\mathrm{LC}_{50}=8.50\right.$,
9.58, 15.26 and 10.35; $\mathrm{LC}_{90}=18.02,20.00,28.88$ and $21.51 \mu \mathrm{g}$ $\left.\mathrm{mL}^{-1}\right)$ and the $\mathrm{LC}_{50}$ and $\mathrm{LC}_{90}$ values of the pupae $\left(\mathrm{LC}_{50}=5.48\right.$, 9.60 and 3.99; $\mathrm{LC}_{90}=14.46,20.56$ and $11.10 \mu \mathrm{g} \mathrm{mL}^{-1}$ ) were obtained from the present study.

FTIR spectroscopy was used to identify the functional groups of the active compounds based on the peak value in the infrared region. FTIR analysis of the ethyl acetate mycelium extract showed the presence of prominent bands due to the $\mathrm{O}-\mathrm{H}$ group of hydrogen-bonded alcohols or phenols (3420.94), $=\mathrm{C}-\mathrm{H}$ aromatics (3002.58), C-H alkanes (2916.88), $-\mathrm{C} \equiv \mathrm{C}-$ nitriles (2122.99), $-\mathrm{C}=\mathrm{C}-$ alkanes (1654.84), $\mathrm{C}-\mathrm{H}$ alkanes (1436.22), C-C aromatics (1409.89), C-O carboxylic acids (1315.64), C-N aliphatic amines (1021.42), $=\mathrm{C}-\mathrm{H}$ alkenes (953.59), $\mathrm{N}-\mathrm{H}$ primary amines (901.85) and $\mathrm{C}=\mathrm{O}$ ketones $(706.10) \mathrm{cm}^{-1}$ (Fig. 2 and Table 5).

The GC-MS results obtained from the ethyl acetate extract of B. bassiana indicated the presence of six major compounds viz. 9,12-octadecadienoic acid (ZZ)- (63.16\%), $n$-hexadecanoic acid (21.28\%), octadecanoic acid, phenyl methyl ester (10.45\%), dehydroegosterol 3,5-dinitrobenzoate (1.86\%), squalene (1.66\%), and bis[3-(3,5-di-tert-butyl-4-hydroxyphenyl)prophyl] maleate $(1.56 \%)$ (Fig. 3 and Table 6$)$. Hence, the isolated bioactive compounds obtained from the B. bassiana derived products, with proven potential as an insecticide, can play an important role in the interruption of the transmission of mosquito-borne diseases. The larvicidal and pupicidal activity of the ethyl acetate extract may be due to the presence of major bioinsecticide constituents such as 9,12-octadecadienoic acid (ZZ)- and $n$-hexadecanoic acid.

HPLC analysis of the ethyl acetate mycelium extract of $B$. bassiana and the $n$-hexadecanoic acid standard showed a similar chromatographic peak (at the retention time 3.383 and $3.378 \mathrm{~min}$ ) (Fig. 4a and b).

\section{Discussion}

Microbial sources serve as a guide for the isolation of several bioactive compounds particularly mosquito control agents. The entomopathogenic fungi have the ability to directly infect the 
Table 2 The larvicidal activity of $B$. bassiana fungal mycelium extract (methanol) against the larvae of An. stephensi, Cx. quinquefasciatus and Ae. aegypti (after $24 \mathrm{~h}$ of exposure) ${ }^{a}$

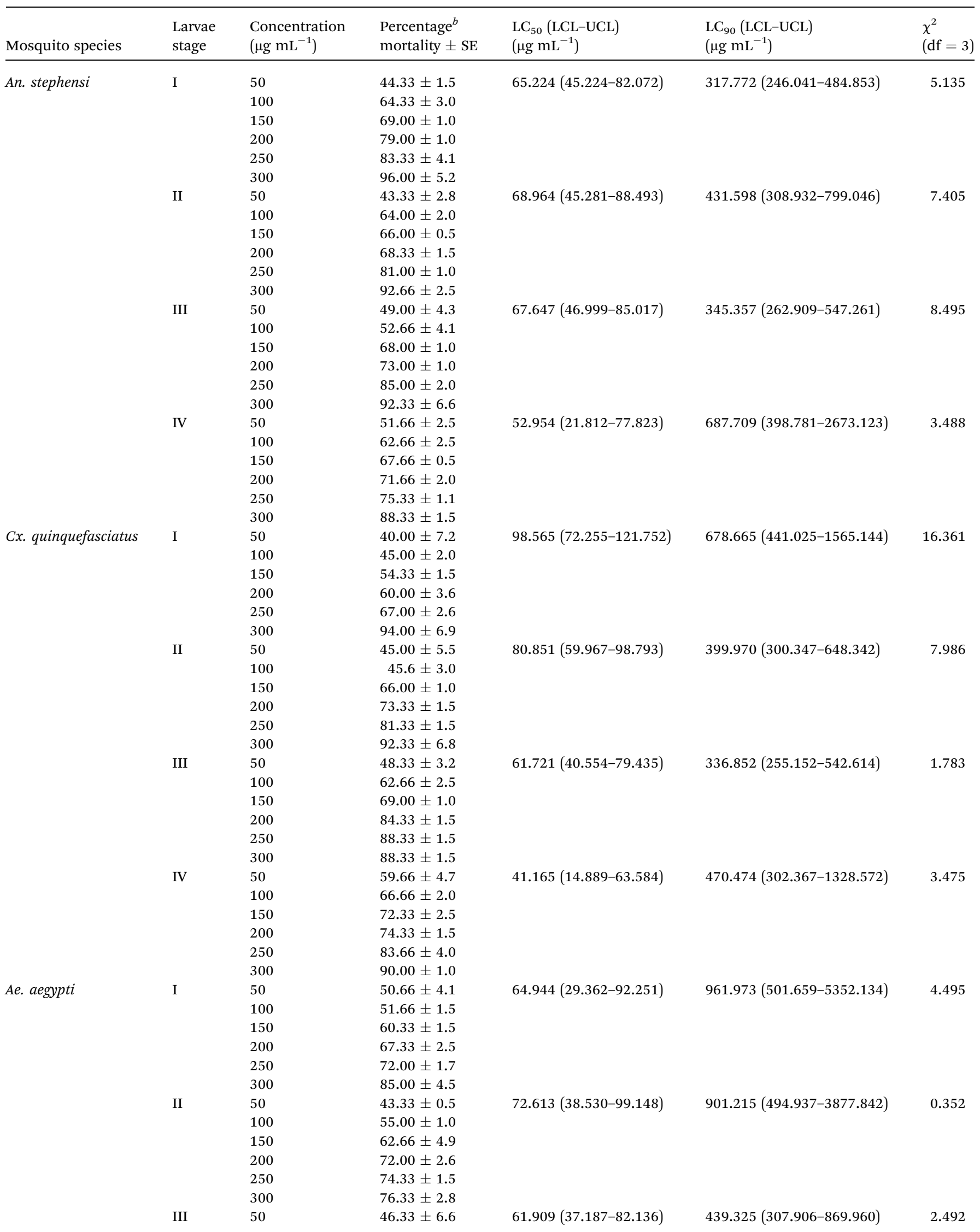


Table 2 (Contd.)

\begin{tabular}{|c|c|c|c|c|c|c|}
\hline Mosquito species & $\begin{array}{l}\text { Larvae } \\
\text { stage }\end{array}$ & $\begin{array}{l}\text { Concentration } \\
\left(\mu \mathrm{g} \mathrm{mL}^{-1}\right)\end{array}$ & $\begin{array}{l}\text { Percentage }^{b} \\
\text { mortality } \pm \mathrm{SE}\end{array}$ & $\begin{array}{l}\mathrm{LC}_{50}(\mathrm{LCL}-\mathrm{UCL}) \\
\left(\mu \mathrm{g} \mathrm{mL}^{-1}\right)\end{array}$ & $\begin{array}{l}\mathrm{LC}_{90}(\mathrm{LCL}-\mathrm{UCL}) \\
\left(\mu \mathrm{g} \mathrm{mL}^{-1}\right)\end{array}$ & $\begin{array}{l}\chi^{2} \\
(\mathrm{df}=3)\end{array}$ \\
\hline & \multirow{8}{*}{ IV } & 100 & $63.00 \pm 2.0$ & \multirow{8}{*}{$57.651(22.651-84.807)$} & \multirow{8}{*}{$916.043(478.320-5338.628)$} & \multirow{8}{*}{0.937} \\
\hline & & 200 & $71.00 \pm 1.0$ & & & \\
\hline & & 250 & $84.00 \pm 1.0$ & & & \\
\hline & & 300 & $85.00 \pm 1.7$ & & & \\
\hline & & 150 & $67.60 \pm 2.0$ & & & \\
\hline & & 200 & $71.00 \pm 1.0$ & & & \\
\hline & & 250 & $76.66 \pm 3.0$ & & & \\
\hline & & 300 & $79.66 \pm 4.7$ & & & \\
\hline
\end{tabular}

${ }^{a}$ Control (deionized water) - nil mortality. $\mathrm{LC}_{50}$ - lethal concentration that kills $50 \%$ of the exposed larvae, $\mathrm{LC}_{90}-$ lethal concentration that kills $90 \%$ of the exposed larvae, $\mathrm{LCL}=$ lower confidence limit, $\mathrm{UCL}=$ upper confidence limit, df degree of freedom, $\chi^{2}-$ chi-square values are significant at $P<$ 0.05 levels. ${ }^{b}$ The mean value of five replicates $( \pm \mathrm{SE})$.

Table 3 The pupicidal activity of B. bassiana mycelium extract (ethyl acetate) against An. stephensi, Cx. quinquefasciatus and Ae. aegypti ${ }^{a}$

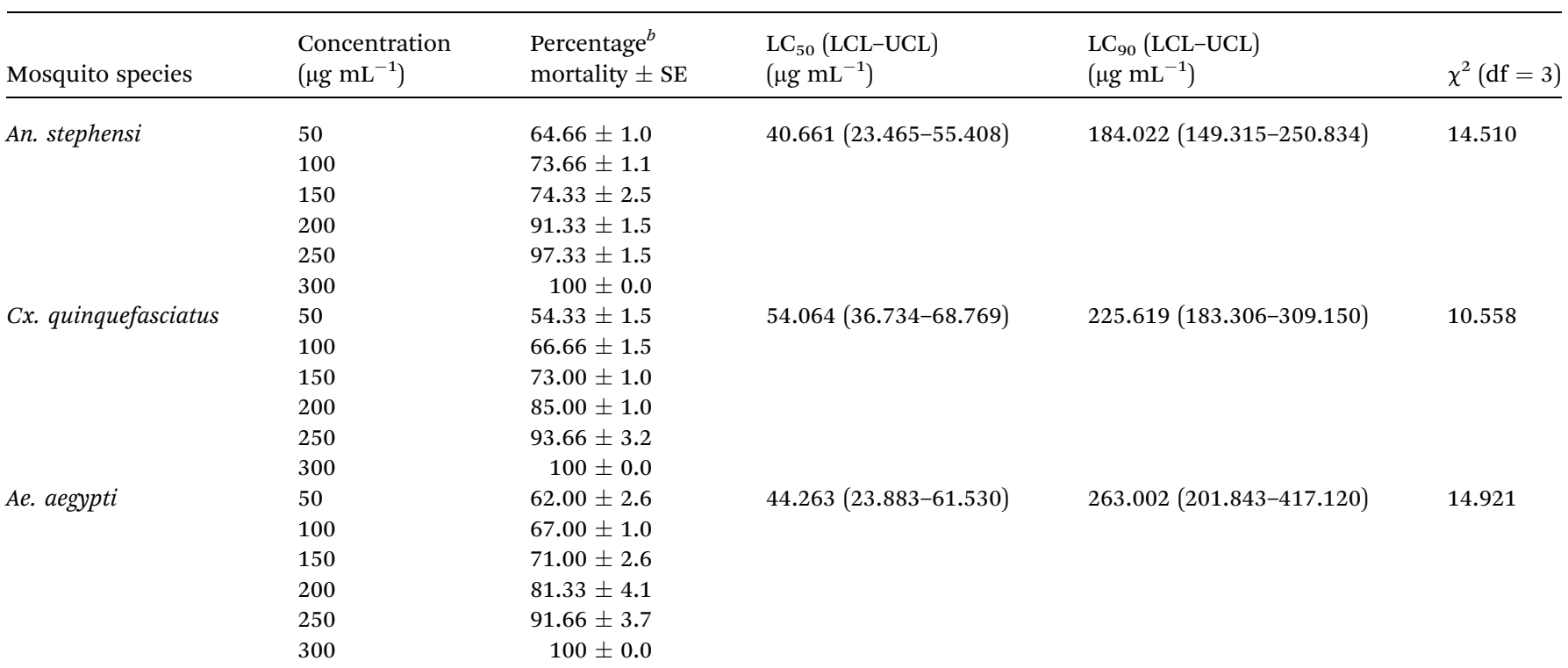

${ }^{a}$ Control (deionized water) - nil mortality. $\mathrm{LC}_{50}$ - lethal concentration that kills $50 \%$ of the exposed larvae, $\mathrm{LC}_{90}-$ lethal concentration that kills $90 \%$ of the exposed larvae, $\mathrm{LCL}=$ lower confidence limit, $\mathrm{UCL}=$ upper confidence limit, df degree of freedom, ${ }^{*} \chi^{2}-$ chi-square values are significant at $P$ $<0.05$ levels. ${ }^{b}$ The mean value of five replicates $( \pm \mathrm{SE})$.

host insect by penetrating into the cuticle and do not require ingesting by the insect to cause diseases. The fungi have a very narrow range and significant progress has been made in recent years towards the improvement of environmentally benign spores and mycelium-based biocontrol agents for mosquito populations. Fungal biocontrol agents have cheap inputs of unsafe synthetic chemical pesticides in agriculture, horticultural and forest systems. ${ }^{14}$ The results of fungal identification showed conidiogenous cells of $B$. bassiana densely clustered in whorls, globose or flask-like base, hyaline, smooth and short. The new conidium, giving a distinct zig-zag appearance in its colonies on PDA were round and flat, like a hyaline film from the radial growing mycelium. Similar results from $B$. bassiana were reported by Draganova et al. ${ }^{38} \mathrm{~B}$. bassiana (Balsamo) is considered a very important and promising fungal agent for use in the control of insects. ${ }^{39}$ The fungus causes high mortalities in mosquito populations, as tested in numerous laboratories; Neetu Vyas et al. ${ }^{\mathbf{4}}$ reported that Lagenidium giganteum fungus metabolites showed $100 \%$ mortality in first instar larvae against An. stephensi, Ae. aegypti, and Cx. quinquefasciatus. Mohanty and Prakash $^{\mathbf{4 1}}$ have described that the filtrate metabolites of Trichophyton ajelloi are effective on the larvae of two mosquito species, Cx. quinquefasciatus and An. stephensi. The culture filtrate metabolites of Chrysosporium tropicum were also found to be toxic and showed an $\mathrm{LC}_{50}$ and $\mathrm{LC}_{90}$ toxicity for all larval instars of An. stephensi tested at different concentrations. 


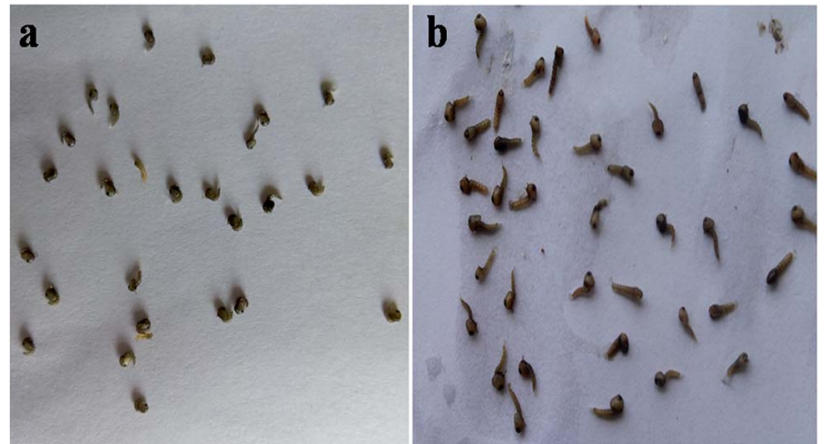

Fig. 1 The pupicidal efficacy of the ethyl acetate extracts of B. bassiana against Cx. quinquefasciatus after $24 \mathrm{~h}$ of exposure: (a) control pupa, (b) pupa treated at a concentration of $300 \mu \mathrm{g} \mathrm{mL}$.

The present study exhibited that the bioactive metabolites of B. bassiana have larvicidal and pupicidal activity against Anopheles, Culex and Aedes mosquitoes. These metabolites may destroy the cuticle layer of the larvae and pupae, which leads to the death of the larvae and pupa. A similar study has been reported by Ababutain et al. ${ }^{42}$ which identified Streptomyces sp. having better mosquitocidal properties. The use of fungus and their products are virulent and are a promising alternative insecticidal control agent. ${ }^{43}$ The efficacy of the insecticidal activity of B. bassiana products against the larvae of An. stephensi, Cx. quinquefasciatus and Ae. aegypti larvae showed that the $\mathrm{LC}_{50}$ and $\mathrm{LC}_{90}$ values for $C x$. quinquefasciatus and Ae. aegypt $i$ were higher than An. stephensi. The $\mathrm{LC}_{50}$ values for the $1^{\text {st }}$ to $4^{\text {th }}$ instar larvae values were observed to be as follows: 65.22, 68.96, 67.64 and 52.95; $\mathrm{LC}_{90}=317.77,431.59,345.35$ and $687.70 \mu \mathrm{g}$ $\mathrm{mL}^{-1}$, respectively. In the present study, after the treatment of the various larval stages of An. stephensi, Cx. quinquefasciatus and Ae. aegypti with the B. bassiana mycelia extracts at different concentrations, $100 \%$ mortality was observed based on the dose-dependent manner. Recently, Kovendan et al. ${ }^{44}$ studied $B$. thuringiensis var. israelensis against the larvae of $C x$. quinquefasciatus at different concentrations. The $\mathrm{LC}_{50}$ and $\mathrm{LC}_{90}$ values were reported as follows: the $\mathrm{LC}_{50}$ value of I instar was $9.332 \%$, II instar was $9.832 \%$, III instar was $10.212 \%$, and IV instar was $10.622 \%$, whereas the $\mathrm{LC}_{90}$ value of I instar was $15.225 \%$, II instar was $15.508 \%$, III instar was $15.887 \%$ and IV instar was $15.986 \%$. Similar studies have been carried out by several researchers using bacteria Bacillus thuringiensis, ${ }^{45,46}$ Bacillus sphaericus $^{47}$ and fungus Trichoderma viride ${ }^{48}$ and Actinobacteria ${ }^{49}$ entomopathogenic fungi Metarhizium, ${ }^{50}$ Trichophyton, $^{41}$ Tolypocladium, ${ }^{51}$ Chrysosporium ${ }^{52}$ and Lagenidium ${ }^{53}$ were reported as potential insecticidal agents.

The outcome of present study proved that mycelium extract of B. bassiana had a broad spectrum larval mortality against $A n$. stephensi, Cx. quinquefasciatus and Ae. aegypti and the values were found to be as follows: for An. stephensi, $\mathrm{LC}_{50}=65.22$, 68.96, 67.64, and 52.95; $\mathrm{LC}_{90}=317.77,431.59,345.35$ and $687.70 \mu \mathrm{g}$ $\mathrm{mL}^{-1}$; for Cx. quinquefasciatus, $\mathrm{LC}_{50}=98.56,80.85,61.72$, and 41.16; $\mathrm{LC}_{90}=678.66,399.97,336.85$ and $470.47 \mu \mathrm{g} \mathrm{mL} \mathrm{L}^{-1}$ and for Ae. aegypti, $\mathrm{LC}_{50}=64.94,72.61,61.90$ and $57.65 ; \mathrm{LC}_{90}=961.97$, 901.21, 439.32 and $916.04 \mu \mathrm{g} \mathrm{mL}{ }^{-1}$. Similarly, Vijayan and Balaraman ${ }^{54}$ isolated 94 actinomycetes from marine soil samples collected at different locations, out of which 35 samples exhibited improved larvicidal activity against $C x$. quinquefasciatus, An. stephensi and Ae. aegypti with $\mathrm{LC}_{50}$ values in the range of $1-3 \mu \mathrm{L}$ $\mathrm{mL}^{-1}$.

The larval and pupal mortality of $C x$. quinquefasciatus after $24 \mathrm{~h}$ of treatment with the $n$-hexadecanoic acid standard

Table 4 The pupicidal activity of $B$. bassiana mycelium extract (methanol) against An. stephensi, Cx. quinquefasciatus and Ae. aegypti ${ }^{a}$

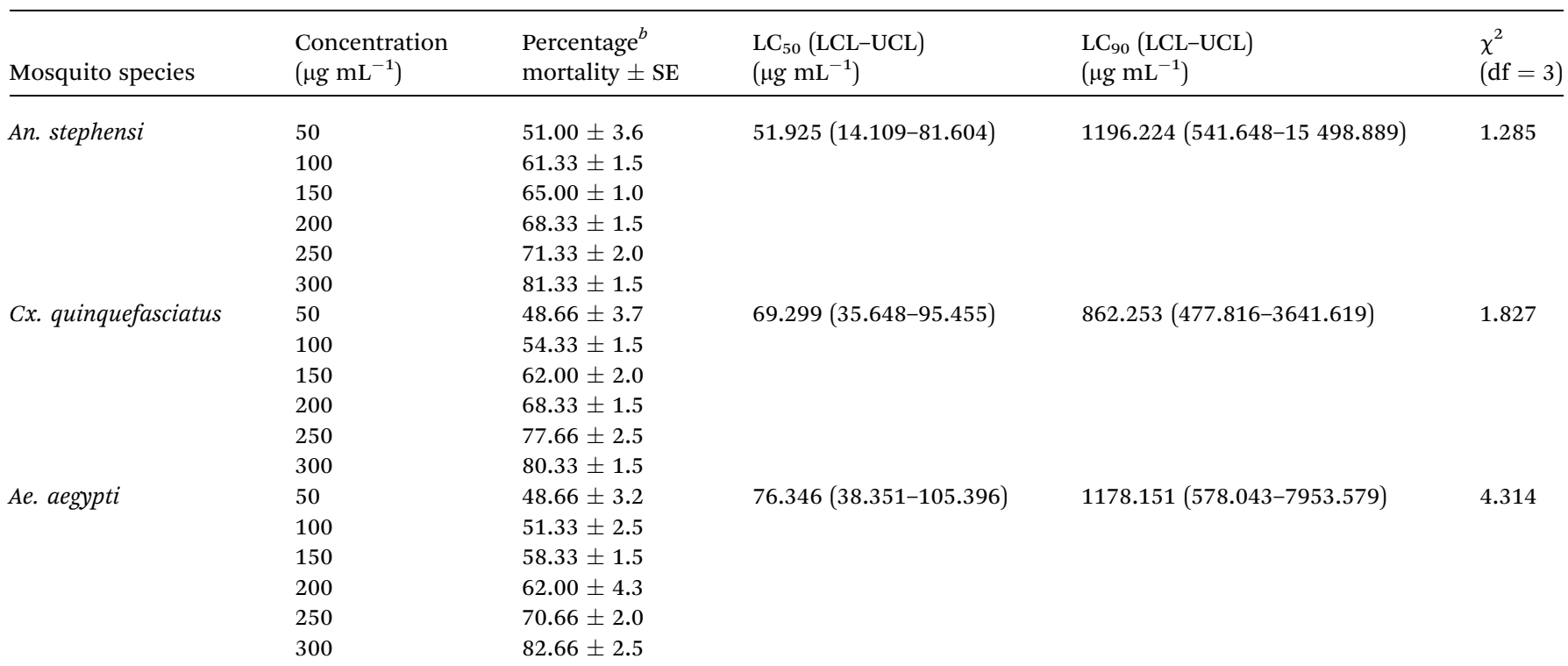

${ }^{a}$ Control (deionized water) - nil mortality. $\mathrm{LC}_{50}$ - lethal concentration that kills $50 \%$ of the exposed larvae, $\mathrm{LC}_{90}-$ lethal concentration that kills $90 \%$ of the exposed larvae, $\mathrm{LCL}=$ lower confidence limit, $\mathrm{UCL}=$ upper confidence limit, df degree of freedom, $\chi^{2}$ - chi-square values are significant at $P<$ 0.05 levels. ${ }^{b}$ The mean value of five replicates $( \pm \mathrm{SE})$. 


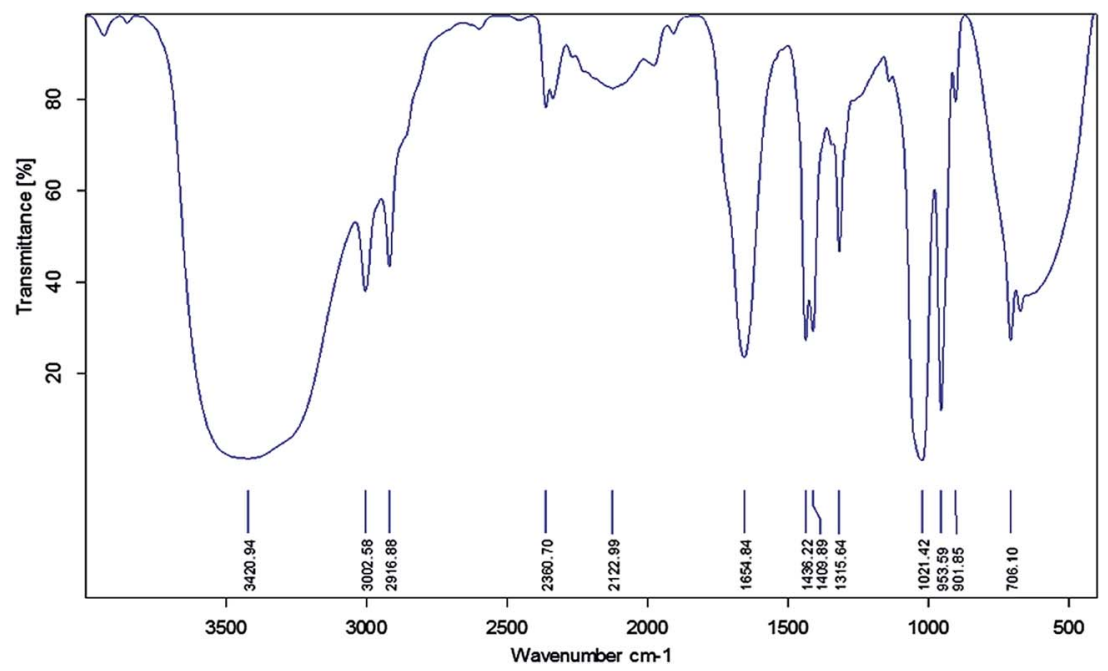

Fig. 2 FTIR analysis of the ethyl acetate mycelia extract obtained from B. bassiana.

Table 5 The FTIR spectrum of the ethyl acetate mycelium extract obtained from $B$. bassiana

\begin{tabular}{lll}
\hline Observed wavenumber $\left(\mathrm{cm}^{-1}\right)$ & Functional group & Bonding pattern \\
\hline 3420.94 & O-H stretch alcohols or phenols & Strong, broad \\
3002.58 & $=\mathrm{C}-\mathrm{H}$ stretch aromatics & Sharp \\
2916.88 & $\mathrm{C}-\mathrm{H}$ alkanes & Medium \\
2122.99 & $-\mathrm{C} \equiv \mathrm{C}-$ stretch nitriles & Medium \\
1654.84 & $-\mathrm{C}=\mathrm{C}-$ stretch alkanes & Medium \\
1436.22 & $\mathrm{C}-\mathrm{H}$ bend alkanes & Medium \\
1409.89 & $\mathrm{C}-\mathrm{C}$ stretch aromatics & Sharp \\
1315.64 & $\mathrm{C}-\mathrm{O}$ stretch alcohols, carboxylic acids, esters, ethers & Medium \\
1021.42 & $\mathrm{C}-\mathrm{N}$ stretch aliphatic amines & Sharp \\
953.59 & $=\mathrm{C}-\mathrm{H}$ bending alkenes & Strong, broad \\
901.85 & $\mathrm{~N}-\mathrm{H}$ wagging primary amines & Sharp
\end{tabular}

showed the highest larvicidal $\left(\mathrm{LC}_{50}=2.27\right.$ and $\mathrm{LC}_{90}=15.91 \mu \mathrm{g}$ $\mathrm{mL}^{-1}$ ) and pupal toxicity $\left(\mathrm{LC}_{50}=0.69\right.$ and $\left.\mathrm{LC}_{90}=4.38 \mu \mathrm{g} \mathrm{mL} \mathrm{mL}^{-1}\right)$ than An. stephensi and Ae. aegypti. Similarly, Rahuman et al. ${ }^{55}$ reported a bioassay-guided fractionation of the acetone extract of Feronia limonia, which was shown as a potent mosquito larvicide, identified as $n$-hexadecanoic acid and found to be effective against fourth instar larvae of Ae. aegypti, Cx. quinquefasciatus and An. stephensi. Similarly, Sivakumar et al. ${ }^{31}$ found the larvicidal and repellent activity of pure tetradecanoic acid against Ae. aegypti and $C x$. quinquefasciatus. The $\mathrm{LC}_{50}$ values were 14.08 and $25.10 \mu \mathrm{g} \mathrm{mL}^{-1}$. More recently, Srinivasan et $a{ }^{56}$ reported the larvicidal potential of isolated thujone against the $4^{\text {th }}$ instar larvae of Ae. aegypti $\left(\mathrm{LC}_{50}=4.23 \mathrm{mg} \mathrm{L}^{-1}\right)$ and An. stephensi $\left(\mathrm{LC}_{50}=3.30 \mathrm{mg} \mathrm{L}^{-1}\right)$. Fungal secondary metabolites have play an important roles in pathogenesis and the larvicidal activity, which can help in controlling mosquito populations and reduce the spread of vector borne diseases. Acremonium ethyl acetate metabolites were found to be more effective against Ae. aegypti and Cx. quinquefasciatus, followed by An. stephensi larvae. Furthermore, the pathogenicity of Acremonium sp. was also reported to possess good parasitic properties. ${ }^{57}$ Similarly, Stanly Pradeep et al. ${ }^{58}$ proved that $F$. oxysporum metabolites are more effective against An. stephensi than $C x$. quinquefasciatus larvae.

The FTIR results indicated that the ethyl acetate mycelium extract showed the presence of chemical bands due to $\mathrm{O}-\mathrm{H}$ group hydrogen-bonded alcohols or phenols (3420.94), $=\mathrm{C}-\mathrm{H}$ aromatics (3002.58), C-H alkanes (2916.88), $-\mathrm{C} \equiv \mathrm{C}-$ nitriles (2122.99), $-\mathrm{C}=\mathrm{C}-$ alkanes (1654.84), $\mathrm{C}-\mathrm{C}$ aromatics (1409.89), C-O carboxylic acids or alcohols (1315.64), C-N aliphatic amines (1021.42), $\mathrm{N}-\mathrm{H}$ primary amines (901.85) and $\mathrm{C}=\mathrm{O}$ ketones (706.10) $\mathrm{cm}^{-1}$. Similar functional groups were obtained by Nagajyothi et al. ${ }^{59}$ The GC-MS analysis results revealed that the larvicidal and pupicidal activity of mycelium ethyl acetate extracts from $B$. bassiana were exhibited due to six major compounds, namely 9,12-octadecadienoic acid (ZZ)- (63.16\%), n-hexadecanoic acid (21.28\%), octadecanoic acid, phenyl methyl ester (10.45\%), dehydroegosterol 3,5-dinitrobenzoate (1.86\%), squalene (1.66\%), bis[3-(3,5-di-tert-butyl-4-hydroxyphenyl)prophyl]maleate (1.56\%). Earlier, Ragavendran and Natarajan $^{60}$ reported that the Aspergillus terreus ethyl acetate extract contains six bioactive compounds and its constituents 


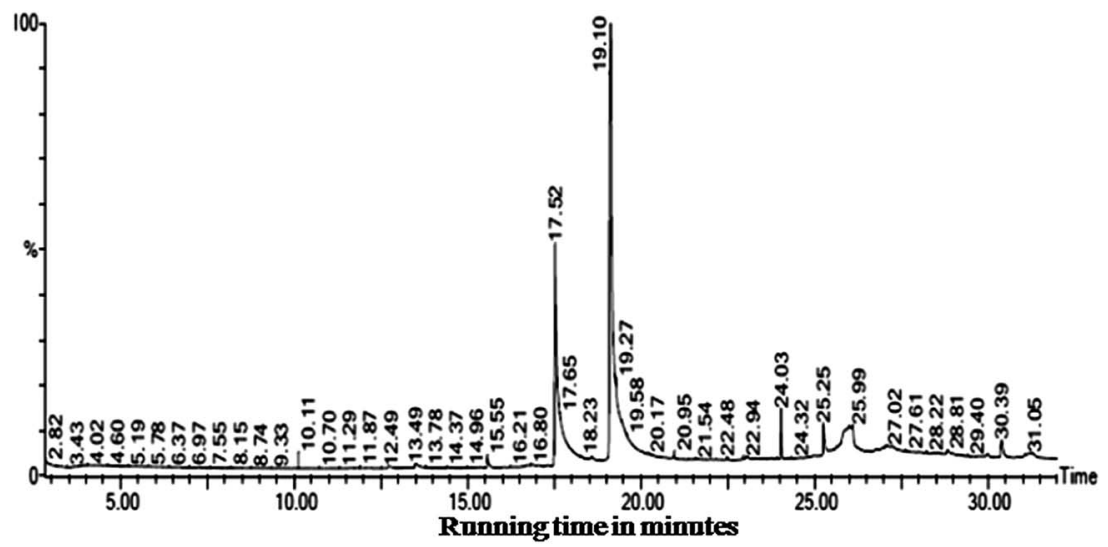

Fig. 3 The insecticidal compounds identified in the ethyl acetate mycelium extracts obtained from B. bassiana.

Table 6 The major bioactive compounds identified in the ethyl acetate mycelium extracts of $B$. bassiana using GC-MS analysis ${ }^{a}$

\begin{tabular}{|c|c|c|c|c|c|c|}
\hline Rt & Area & Area $\%$ & $\begin{array}{l}\text { Molecular } \\
\text { weight/formula }\end{array}$ & Compound name & Biological activity & References \\
\hline 17.519 & 80887080.0 & 21.286 & $256, \mathrm{C}_{16} \mathrm{H}_{32} \mathrm{O}_{2}$ & $n$-Hexadecanoic acid & Nematicide, pesticide & $\begin{array}{l}\text { Ragavendran and Natarajan } 2015,{ }^{60} \\
\text { Rajeswari et al. } 2012,^{73} \\
\text { Zahir Hussain } \text { et al. } 2010 \text { (ref. } 74 \text { ) }\end{array}$ \\
\hline 19.120 & 240006224.0 & 63.160 & $280, \mathrm{C}_{18} \mathrm{H}_{32} \mathrm{O}_{2}$ & $\begin{array}{l}\text { 9,12-Octadecadienoic } \\
\text { acid (ZZ)- }\end{array}$ & Larvicide & Velu et al. 2014 (ref. 75) \\
\hline 25.253 & 7088480.0 & 1.865 & $588, \mathrm{C}_{35} \mathrm{H}_{44} \mathrm{O}_{6} \mathrm{~N}_{2}$ & $\begin{array}{l}\text { Dehydroegosterol } \\
\text { 3,5-dinitrobenzoate }\end{array}$ & Not known & Nil \\
\hline 26.098 & 39740176.0 & 10.458 & $374, \mathrm{C}_{25} \mathrm{H}_{42} \mathrm{O}_{2}$ & $\begin{array}{l}\text { Octadecanoic acid, } \\
\text { phenyl methyl ester }\end{array}$ & $\begin{array}{l}\text { Hypocholesterolemic } \\
\text { and nematicide }\end{array}$ & $\begin{array}{l}\text { Dr Duke's Phytochemical } \\
\text { and Ethnobotanical Database }\end{array}$ \\
\hline 30.390 & 5952307.5 & 1.566 & $608, \mathrm{C}_{38} \mathrm{H}_{56} \mathrm{O}_{6}$ & $\begin{array}{l}\text { Bis[3-(3,5-di-tert-butyl-4- } \\
\text { hydroxyphenyl) } \\
\text { prophyl]maleate }\end{array}$ & Not known & Nil \\
\hline
\end{tabular}

showed better larvicidal and the pupicidal effects on selected mosquito vectors, namely An. stephensi $\left(\mathrm{LC}_{50}=97.410\right.$, 102.551, 29.802 and 8.907; $\mathrm{LC}_{90}=767.957,552.546,535.474$

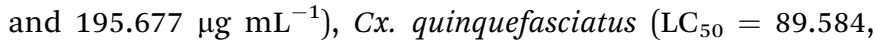
74.689, 68.265 and 67.40; $\mathrm{LC}_{90}=449.091,337.355,518.793$ and $\left.237.347 \mu \mathrm{g} \mathrm{mL}^{-1}\right)$ and Ae. aegypti $\left(\mathrm{LC}_{50}=83.541,84.418\right.$, 80.407 and 95.926; $\mathrm{LC}_{90}=515.464,443.167,387.910$ and $\left.473.998 \mu \mathrm{g} \mathrm{mL}^{-1}\right)$. Pupicidal activity was also reported against An. stephensi $\left(\mathrm{LC}_{50}=25.228 ; \mathrm{LC}_{90}=140.487 \mu \mathrm{g} \mathrm{mL} \mathrm{m}^{-1}\right), C x$. quinquefasciatus $\left(\mathrm{LC}_{50}=54.525 ; \mathrm{LC}_{90}=145.366 \mu \mathrm{g} \mathrm{mL}{ }^{-1}\right)$ and Ae. aegypti $\left(\mathrm{LC}_{50}=10.536 ; \mathrm{LC}_{90}=63.762 \mu \mathrm{g} \mathrm{\textrm {mL } ^ { - 1 }}\right)$. Squalene is considered as an important substance for practical and clinical use with huge potential in the nutraceutical and pharmaceutical industries. ${ }^{61}$ Similarly, Thimiri et al. ${ }^{62}$ reported that the Streptomyces sp. produced the isolated compound (2S,5R,6R)-2-hydroxy-3,5,6-trimethyloctan-4-one observed against the larvae of $R$. microplus $\left(\mathrm{LC}_{50}=88.74 \mathrm{ppm} ; r^{2}=0.865\right)$, An. subpictus $\left(\mathrm{LC}_{50}=162.59 \mathrm{ppm} ; r^{2}=0.817\right)$ and $C x$. quinquefasciatus $\left(\mathrm{LC}_{50}=120.15 \mathrm{ppm} ; r^{2}=0.782\right)$. Kumar Saurav et al. ${ }^{63}$ reported that Streptomyces VITSVK5 sp. yielded the bioactive/ isolated compound 5-(2,4-dimethylbenzyl) pyrrolidin-2-one, which had larvicidal activity against the larvae of $R$. microplus $\left(\mathrm{LC}_{50}=210.39 \mathrm{ppm}, r^{2}=0.873\right)$, An. stephensi $\left(\mathrm{LC}_{50}=\right.$ $\left.169.38 \mathrm{ppm}, r^{2}=0.840\right)$ and $C x$. tritaeniorhynchus $\left(\mathrm{LC}_{50}=\right.$ $\left.198.75 \mathrm{ppm}, r^{2}=0.887\right)$. Previously, some researchers have reported the insecticidal activity of isolated compounds obtained from the species of Streptomyces, namely tetranectin, ${ }^{64}$ avermectins, ${ }^{65}$ faeriefungin ${ }^{66}$ and macrotetrolides. ${ }^{67}$

The HPLC analysis of the ethyl acetate mycelium extract was compared with the $n$-hexadecanoic acid standard and they showed a similar chromatographic peak (at a retention time of 3.383 and $3.378 \mathrm{~min}$ ). The HPLC results were in agreement with the earlier reports of Ragavendran and Natarajan, ${ }^{60}$ and Manilal et al. ${ }^{68}$ who obtained (15.31 and $42 \%$ ) $n$-hexadeconoic acid using different extracts. Previously, several researchers have isolated $n$-hexadecanoic acid from different plants and microbes i.e. Vitex altissima, $V$. negundo and $V$. trifolia, ${ }^{69}$ Aspergillus fumigatus $^{70}$ A. versicolor ${ }^{71}$ and Pestalotiopsis sp. ${ }^{72}$ The use of fungus 


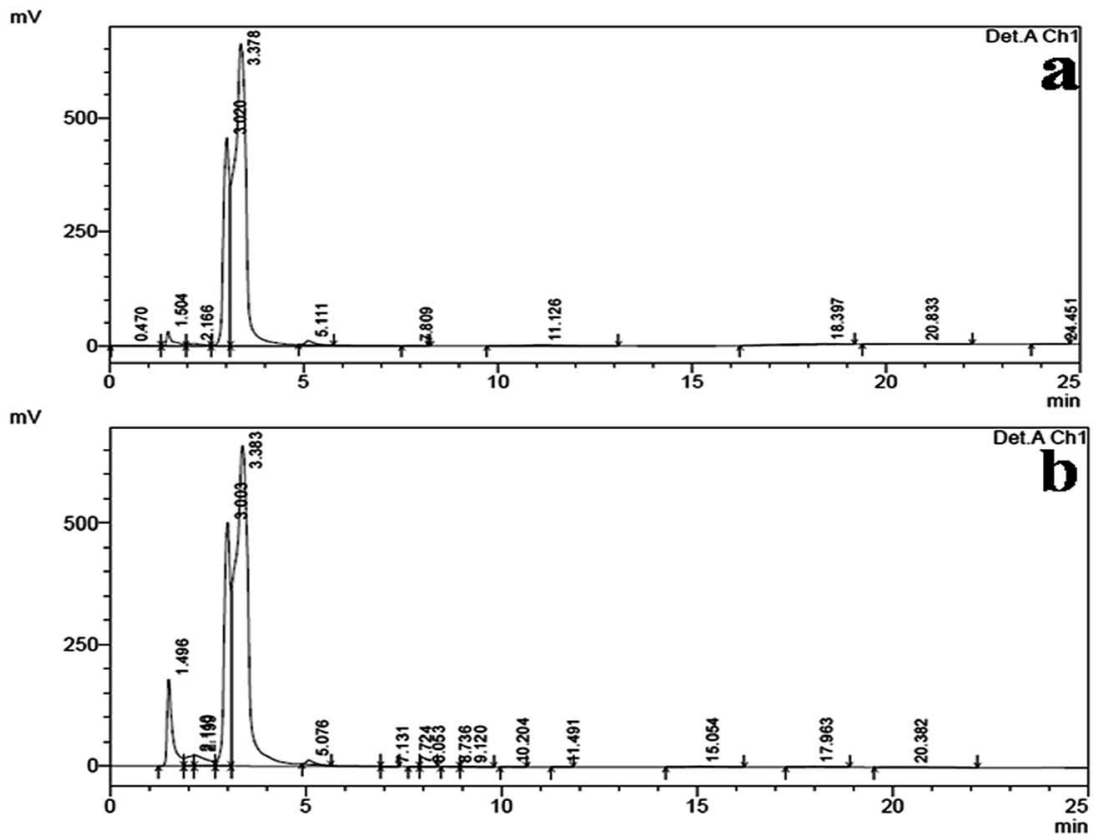

Fig. 4 (a) The HPLC chromatogram of the $n$-hexadecanoic acid standard and (b) the HPLC chromatogram of the ethyl acetate mycelium extract obtained from $B$. bassiana.

based products would be cheaper, target-specific, self-sustained and highly toxic to mosquitoes, even at low doses.

\section{Conclusion}

Our findings confirm a promising as well as a novel biological based strategy to be integrated with additional control measures to reduce the global rate of vector-borne disease transmission. At a concentration of $300 \mu \mathrm{g} \mathrm{mL} \mathrm{m}^{-1}$ of $B$. bassiana ethyl acetate extract, 90\% mortality was observed within $18 \mathrm{~h}$ against An. stephensi and $C x$. quinquefasciatus, followed by Ae. aegypti and 100\% pupal mortality was observed at higher concentrations. The pupal toxicity of the mosquitoes was mainly based on the dose-dependent effect against An. stephensi, Cx. quinquefasciatus and Ae. aegypti. GC-MS analysis of the ethyl acetate extract of $B$. bassiana identified six major components, i.e. 9,12-octadecadienoic acid (ZZ)- (63.16\%), $n$-hexadecanoic acid (21.28\%), octadecanoic acid, phenyl methyl ester (10.45\%), dehydroegosterol 3,5-dinitrobenzoate (1.86\%), squalene $(1.66 \%)$ and bis[3-(3,5-di-tert-butyl-4-hydroxyphenyl) prophyl]maleate $(1.56 \%)$. The bioactive compounds may be responsible for the larvicidal and pupicidal activity against $A n$. stephensi, Cx. quinquefasciatus and Ae. aegypti mosquitoes. In addition, HPLC analysis of the ethyl acetate mycelium extract of $B$. bassiana and the $n$-hexadecanoic acid standard show a similar chromatographic peak (at a retention time of 3.383 and $3.378 \mathrm{~min}$ ). Moreover, these metabolites can be used for the development of new insecticidal formulations to control vector borne diseases because they constitute a rich source of bioactive compounds that are more effective, eco-friendly, non-toxic, and potentially suitable for use in the management of target insects/pests. Further studies are ongoing for the isolation of pure active compounds and determination of the mode of action so as to recommend an ecofriendly measure for the control of mosquitoes.

\section{Authors' contributions}

Conceived and designed the experiments: CR and DN Performed the experiments and analyzed the data: CR. CR and DN analyzed and interpreted the data and wrote the manuscript. Revision of the manuscript: DN and NKD Finally, all authors have read and approved the final manuscript.

\section{Compliance with ethical standards}

All applicable international and national guidelines for the care and use of animals were followed. All procedures performed in the studies involving animals were in accordance with the ethical standards of the institution or practice at which the studies were conducted.

\section{Conflict of interest}

The authors declare that they have no conflict of interest in this research article.

\section{Acknowledgements}

The first author acknowledged to the Periyar University for providing financial support under University Fellowship Scheme (Ref No. PU/A\&A-3/URF/2014). We would like to thank the Department of Biotechnology, School of Biosciences, Periyar University for providing necessary infrastructural facility for carrying out this study successfully. We also thank the Institute of Vector Control and Zoonoses (IVCZ) Hosur for supplying mosquitoes and we thank the Vellore Institute of Technology (VIT) for GC-MS analysis of our bio-samples. The authors would like to express their sincere thanks to Prof. P. Perumal, Marine 
Biotechnology Laboratory, Department of Biotechnology, Periyar University, Salem, Tamilnadu, India for providing the HPLC instrumental facility for analysis of the samples.

\section{References}

1 V. Corby-Harris, A. Drexler, L. Watkins de Jong, Y. N. Antonova and N. Pakpour, PLoS Pathog., 2010, 6, 110, e1001003.

2 WHO, Larval source management: a supplementary measure for malaria vector controls an operational manual, 2013, pp. 1116.

3 M. Govindarajan, T. Mathivanan, K. Elumalai, K. Krishnappa and A. Anandan, Asian Pac. J. Trop. Biomed., 2011, 1, 43-48.

4 WHO, http://www.who.int/media centre/factsheets/fs102/en/ , 2012.

5 Z. Peng, J. Yang, H. Wang and F. E. R. Simons, Insect Biochem. Mol. Biol., 1999, 29, 909-914.

6 WHO, http://www.who.int/features/factfiles/malaria/en/index. html, 2013.

7 M. Z. Hossam El-Din and S. A. M. Abdelgaleil, J. Agric Res., 2010, 36, 385-401.

8 T. Su and M. S. Mulla, J. Am. Mosq. Control Assoc., 1998, 14, 204-209.

9 S. Poopathi, Journal of Biofertilizers \& Biopesticides, 2012, 3, 1-14.

10 M. Maheu-Giroux and M. C. Castro, PLoS One, 2013, 8, 1-11. 11 EPA, Biopesticide Fact Sheet: Beauveria bassiana strain ATCC. 74040, 2000128818.

12 F. V. A. Howard, R. Guessan, C. J. M. Koenraadt, A. Asidi, F. Marit, M. Akoqbeto, M. B. Thomas, B. G. H. Knols and W. Takken, Malar J., 2010, 3, 1-11.

13 EPA, Biopesticide Registration Action Document: Beauveria bassiana HF23, 2006.

$14 \mathrm{H}$. Strasser, A. Vey and T. Butt, Biocontrol Science and Technology, 2000, 10, 717-735.

15 A. Vey, R. E. Hoagland and T. M. Butt, Toxic metabolites of fungal biocontrol agents. Fungi as biocontrol agents. progress, problems and potential, ed. T. M. Butt, C. Jackson and N. Magan, CABI Publishing, Oxford, UK, 2001, pp. 311-346.

16 E. Quesada-Moraga and A. Vey, Mycol. Res., 2004, 108, 441452.

17 A. K. Charnley and R. J. S. Leger, The role of cuticledegrading enzymes in fungal pathogenesis in insects, $\mathrm{p}$. 267-287, in, Fungal Spore Disease Initiation in Plants and Animals, ed. E. T. Cole and H. C. Hoch, Plenum Press, New York, 1991, p. 555.

18 M. Govindarajan, A. Jebanesan and D. Reetha, Trop. Biomed., 2005, 22, 1-3.

19 N. Haraprasad, S. R. Niranjans, H. S. Prakash, H. S. Shetty and W. Seema, Ind. Biocontrol Sci. Tech., 2001, 11, 251-260.

20 R. A. Samson, Identification: Entomopathogenic Deuteromycetes, in, Microbial Control of Pests and Plant Diseases, ed. H. D. Burges, Academic press, London, 1981, pp. 93-106.

21 R. A. Samson, H. C. Evans and J. P. Latgé, Atlas of Entomopathogenic Fungi, Springer-Verlag, Berlin, 1988.
22 G. S. Hoog de, Stud. Mycol., 1972, 1, 1-41.

23 J. M. Gardner and J. S. Pillai, Mycopathologia, 1987, 97, 7782.

24 G. N. Belofsky, M. Anguera, P. R. Jensen, W. Fenical and M. Kock, Chem.-Eur. J., 2000, 6, 1355-1360.

25 S. V. Patil, C. D. Patil, B. K. Salunke and R. B. Salunkhe, Trop. Biomed., 2010, 27, 360-365.

26 WHO, 2005, WHO/CDS/WHOPES/GCDPP/2005:13.

27 M. Govindarajan and G. Benelli, J. Parasitol. Res., 2016, 115, 925-935.

28 W. S. Abbott, J. Econ. Entomol., 1925, 18, 265-266.

29 D. J. Finney, Probit analysis, Cambridge University Press, Cambridge, 1971, pp. 76-80.

30 R. R. Rahuman and P. Venketesan, J. Parasitol. Res., 2008, 103, 133-139.

31 R. Sivakumar, A. Jebanesan, M. Govindarajan and P. Rajasekar, Asian Pac. J. Trop. Med., 2011, 4, 706-710.

32 K. V. Bhaskara Rao, K. S. Hemath Naveen, G. Kumar and L. Karthik, Arch. Appl. Sci. Res., 2010, 2, 161-167.

33 M. A. Hossain and M. D. M. Shah Sakari, Asian Pac. J. Trop. Med., 2011, 4, 637-641.

34 M. Junaid Khan, S. Swarnlata and S. Shailendra, J. Ethnopharmacol., 2016, DOI: 10.1016/j.jep.2016.08.021.

35 P. J. Reddy, D. Krishna, U. S. Murthy and K. Jamil, CABIOS, Comput. Appl. Biosci., 1992, 8, 209-213.

36 E. J. Hermanides-Nijihof, (Stud. Mycol.15) Centraalbureau voor Schimecultures, Baarn, 1977, vol. 1, pp. 141-177.

37 S. Seyed Ali, J. Plant Prot. Res., 2010, 50, 159-163.

38 S. A. Draganova, I. Danail, D. Takov and D. Doychev, Pestic. Phytomed., 2010, 25, 59-63.

39 W. B. Shi and M. G. Feng, Biol. Control, 2004, 30, 165-173.

40 N. Vyas, K. K. Dua and S. Prakash, J. Parasitol. Res., 2007, 101, 385-390.

41 S. S. Mohanty and S. Prakash, Curr. Sci., 2004, 86, 323-325.

42 M. Ababutain, K. Zeinab, A. Abdul Azizand Nijla and A. L. Meshhen, Can. J. Pure Appl. Sci., 2012, 6, 1739-1748.

43 E. J. Scholte, K. Ng'habi, J. Kihonda, W. Takken, K. Paaijmans, S. Abdulla and G. F. Killeen, B. G. J. Knols Science, 2005, 10, 1641-1642.

44 K. Kovendan, K. Murugan, S. Vincent and S. Kamalakannan, J. Parasitol. Res., 2011, 109, 1251-1257.

45 K. Balaraman, ICMR Bulletin, 1995, 25, 45-51.

46 G. Prabhakaran, V. Padmanaban and K. Balaraman, J. Biol. Contr., 2000, 14, 63-66.

47 G. Rajendran, S. Sabesan, K. Kuppusamy and K. Balaraman, Entomon, 1991, 16, 213.

48 I. Geetha and K. Balaraman, J Biol Contr, 2001, 15, 93.

49 D. Dhanasekaran, V. Sakthi, N. Thajuddin and A. Panneerselvam, Int. J. Appl. Biol. Pharm. Technol., 2010, 1, 374-381.

50 D. W. Roberts, Some effects of Metarhizium anisopliae and its toxins on mosquito larvae, in Insect pathology and microbial control, ed. Laan PA van der, North-Holland Publishing Company, 1967, pp. 243-246.

51 V. Matha, J. Weiser and J. Olejnicek, Parasitology, 1988, 35, 379-381.

52 A. Priyanka and S. Prakash, J. Am. Mosq. Control Assoc., 2003, 19, 404-407. 
53 N. Vyas, K. K. Dua and S. Prakash, Bull. Bio. Sci., 2006, 4, 65-69. 54 V. Vijayan and K. Balaraman, Indian J. Med. Res., 1991, 93, 115-117.

55 A. A. Rahuman, G. Gopalakrishnan, B. S. Ghouse, S. Arumugam and B. Himalayan, Fitoterapia, 2000, 71, 553-555.

56 R. Srinivasan, D. Natarajan, M. S. Shivakumar, T. Vinuchakkaravarthy and D. Velmurugan, Ind. Crops Prod., 2015, 76, 394-401.

57 G. F. Atkinson, Some diseases of cotton, Albama Polytechnical Inst. Expt. Sta., 1892, 41, 61-65.

58 F. Stanly Pradeep, M. Palaniswamya, S. Ravi, A. Thangamani and B. V. Pradeep, Process Biochem., 2015, 50, 1479-1486.

59 P. C. Nagajyothi, T. V. M. Sreekanth, J. L. Lee and K. D. Lee, J. Photochem. Photobiol., B, 2014, 130, 299-304.

60 C. Ragavendran and D. Natarajan, Environ. Sci. Pollut. Res., 2015, 22, 17224-17237.

61 S. K. Kim and F. Karadeniz, Adv. Food Nutr. Res., 2012, 65, 223-233.

62 L. D. Thimiri, K. Kannabiran, V. Gopiesh Khanna, G. Rajakumar, C. Jayaseelan, T. Santhoshkumar and A. A. Rahuman, J. Parasitol. Res., 2012, 111, 1151-1163.

63 S. Kumar, G. Rajakumar, K. Kannabiran, A. A. Rahuman, K. Velayutham, G. Elango, C. Kamaraj and A. A. Zahir, J. Parasitol. Res., 2013, 112, 215-226.

$64 \mathrm{~K}$. Ando, How to discover new antibiotics for insecticidal use, in Pesticide chemistry: human welfare and the environment. Natural products, ed. T. Takahashi, $\mathrm{H}$.
Yoshioka, T. Misato and S. Matusunaka, Pergamon, New York, 1983, pp. 253-259.

65 S. Pampiglione, G. Majori, G. Petrangeli and R. Romi, Trans. R. Soc. Trop. Med. Hyg., 1985, 79, 797-799.

66 Anonymous, Biotechnol Abstr., 1990, 9, 58.

67 Z. Zizka, J. Weiser, M. Blumauerova and J. Jizba, Cytobios, 1989, 58, 85-91.

68 A. Manilal, S. Sujitha, J. Selvin, C. Shakir and G. Seghal Kiran, Indian J. Exp. Biol., 2009, 78, 161-166.

69 K. Kannathasan, A. Senthilkumar, V. Venkatesalu and M. Chandrasekaran, J. Parasitol. Res., 2008, 103, 999-1001.

70 J. Xu, L. Xianqun, Z. J. Z. Wenhua and T. Renxiang, J. Chem. Pharm. Res., 2014, 6, 893-897.

71 G. Senthilkumar, P. Madhanraj and S. Panneerselvam, Asian J. Pharm. Sci., 2011, 1, 19-21.

72 D. Li, Y. Shihong, P. Proksch, Z. Liang, Q. Li and J. Xu, Afr. J. Biotechnol., 2013, 12, 3802-3806.

73 G. Rajeswari, M. Murugan and V. R. Mohan, Res. J. Pharm., Biol. Chem. Sci., 2012, 3, 301-307.

74 A. Zahir Hussain, I. Aruna and J. Asian, J. Chem., 2010, 22, 3591-3595.

75 K. Velu, D. Elumalai, P. Hemalatha, M. Babu, A. Janaki and P. K. Kaleena, Int. J. Mosq. Res., 2015, 2, 1-08.

76 WHO, Squalene-based adjuvants in vaccines, Global Advisory Committee on Vaccine Safety, 1997.

77 Dr. Duke's Phytochemical and Ethnobotanical Databases compiled by Dr. Jim Duke of the Agricultural Research Service/USDA. 